\title{
Fatores ambientais como coadjuvantes na comunicação e no cuidar do idoso hospitalizado
}

\author{
Environmental factors as supportive components in communication and care for hospitalized elderly \\ Factores ambientales como coadyuvantes en la comunicación y cuidado de ancianos hospitalizados
}

\author{
Teresa Cristina Prochet' ${ }^{1}$, Maria Julia Paes da Silva' \\ 'Universidade de São Paulo, Escola de Enfermagem, Grupo de Estudos e \\ Pesquisa sobre Comunicação em Enfermagem. São Paulo-SP, Brasil.
}

Submissão: 03-03-2011 Aprovação: 19-07-2012

\section{RESUMO}

Estudo exploratório com abordagem qualitativa desenvolvido com 117 graduandos e profissionais da área da saúde, no interior paulista, com o objetivo de identificar os fatores ambientais que interferem na comunicação do profissional da saúde com o idoso. As respostas puderam ser ordenadas e analisadas em sete agrupamentos: fatores sonoros e vibratórios, decorativos e espaciais, luminosos, cores e texturas, térmicos e ventilatórios, higiênicos e de segurança profissional e sinalizadores visuais. Considera-se que a utilização dos fatores ambientais durante o processo de cuidar seja uma possibilidade efetiva do cuidado, uma vez que interfere no bem estar do idoso, na sua recuperação e no relacionamento entre o binômio profissional-idoso.

Descritores: Comunicação não Verbal; Idoso; Ambiente de Instituições de Saúde; Enfermagem.

\section{ABSTRACT}

This exploratory work with a qualitative approach was performed with 117 health professionals and undergraduate students in São Paulo State countryside. The goal was to identify environmental factors that could play a role in health professionals' communication with elderly patients. The findings were organized and grouped in seven categories: sound and vibration factors, decorative and spatial factors, light factors, colors and textures, heat and ventilation factors, hygiene and personal safety factors, and visual signs. It was found that making use of environmental factors while providing care services to the elderly may lead to effective health care. These factors not only interfere with patients' welfare and recovery, but also play a role in the relationship between health professionals and elderly patients

Key words: Nonverbal Communication; Elderly; Health Facility Environment; Nursing.

\section{RESUMEN}

Estudio exploratorio con abordaje cualitativo desarrollado con 117 estudiantes y profesionales del área de la salud, en una provincia de São Paulo, con el objetivo de identificar los factores ambientales que interfieren en la comunicación del profesional de salud con el anciano. Las respuestas pudieron ser ordenadas y analizadas en siete grupos: factores sonoros y vibratorios, decorativos y espaciales, luminosos, colores y texturas, térmicos y de ventilación, higiénicos y de seguridad profesional y señalizadores visuales. Se considera que la utilización de los factores ambientales durante el proceso de cuidar sea una posibilidad de efectiva asistencia, ya que interfiere en el bienestar del anciano, en su recuperación y en el relacionamiento entre el binomio profesional-anciano.

Palabras clave: Comunicación no Verbal; Anciano; Ambiente de Instituciones de Salud; Enfermería. 


\section{INTRODUÇÃO}

A industrialização trouxe além da modernização, a valorização da ciência e o avanço tecnológico. Esses avanços tem se expandido para todos os campos do conhecimento, inclusive na área da saúde. A introdução da informatização e desenvolvimento de equipamentos sofisticados sem dúvida trouxeram ganhos inegáveis como o benefício diagnóstico e terapêutico para o enfrentamento dos problemas de saúde ${ }^{(1)}$. Esse ambiente novo permeado de tecnologia tem exigido uma performance cada vez melhor e atualizada dos profissionais de saúde e,ainda, afetado às relações humanas com o cliente ${ }^{(2)}$.

A ocorrência de ações pouco humanizadas é uma condição presente no cenário do cuidar em gerontologia, uma vez que o profissional envolvido relaciona a ciência e técnica de maneira reduzida. A negligência dos aspectos específicos da pessoa idosa tem ocorrido por desconhecimento da dinâmica existente que perpassa neste tipo de cliente, dentre eles os aspectos comunicacionais necessários e requeridos durante $o$ processo de cuidar ${ }^{(3)}$.

Sabe-se que os profissionais da saúde têm o compromisso de contribuir para o aprimoramento das condições de viver e ser saudável, buscando uma melhor qualidade de vida para todas as pessoas sob sua responsabilidade ${ }^{(2)}$. Neste sentido, cuidado e ambiente estão interligados e devem ser foco da atenção dos profissionais de saúde nos diferentes espaços de cuidado no qual a pessoa idosa está presente ${ }^{(3)}$.

É interessante ressaltar que apesar do cuidar do ambiente ter sido uma preocupação constante na Enfermagem, ele merece ser encarado com atenção e zelo por todos os profissionais de saúde, uma vez ser ele constituído também como espaço social de trabalho, consequentemente, deve possuir características que favoreçam o cuidado com ser humano em sua totalidade e especificidades.

A teoria ambientalista concebe o ambiente em todos os seus aspectos, físico, psicológico e social, uma vez que estes interferem diretamente no conforto e bem estar das pessoas, influenciando na manutenção ou na restauração de sua energia vital. Quando um ou mais aspectos do ambiente encontra-se desequilibrado, o cliente precisa utilizar de maior energia para contrabalancear os fatores estressantes do ambiente, o que consome esforços e fornece desgastes. Sendo assim, é fundamental que os profissionais da saúde organizem e mantenham o ambiente de forma a ajudá-lo(4).

Apesar da ênfase concedida ao ambiente físico, onde ventilação, iluminação, limpeza constituem papel essencial já que, quando adequados, são capazes de manter o organismo em condições favoráveis para o reestabelecimento da saúde, as preocupações da referida teoria incluem os aspectos psicológicos e sociais referentes aos relacionamentos estabelecidos entre profissionais e clientes ${ }^{(4-5)}$. Pode-se afirmar, então, que a comunicação se reveste de importância impar, pois ratifica a ação do cuidar interativo.

Compreende-se comunicação como o agir humano que traz possibilidade das pessoas se relacionarem, compartilhando suas ideias, experiências e emoções. Ao se relacionar, elas sofrem influencias próprias, do outro e do ambiente que o cercam $^{(6)}$; portanto, é uma "via de mão-dupla" que comporta etapas sucessivas que, reunidas, integram-se e formam o que se denomina de comunicação interpessoal.

O ambiente físico se constitui no conjunto de medidas físicas: meio térmico, sonoro, vibratório e luminoso ${ }^{(7)}$. Sua forma, cores, mobílias, bem como as delimitações de espaços, podem ou não facilitar as relações entre os profissionais de saúde e o cliente, aproximar ou distanciar as pessoas, colaborar no processo efetivo da comunicação ou não. Em um sentido mais amplo, o ambiente físico pode compreender tudo que rodeia uma pessoa, podendo instigar fortes sentimentos e atitudes, tanto positivas como negativas nos indivíduos ${ }^{(6)}$.

É oportuno mencionar a proposta do Ministério da Saú$\mathrm{de}^{(7)}$, estabelecida por meio de ambiência na saúde. Esse termo refere-se ao tratamento dado ao espaço físico entendido como espaço social, profissional e de relações interpessoais que deve proporcionar atenção acolhedora, resolutiva e humana. Existem componentes como, por exemplo: morfologia, luz, cheiro, som, arte e cor que atuam como modificadores e qualificadores do espaço, estimulando a percepção ambiental e, quando utilizados com equilíbrio e harmonia, criam ambientes acolhedores, propiciando contribuições significativas no processo de produção de saúde.

Alguns questionamentos foram mobilizados e acabaram por culminar nesse estudo; são eles: onde termina e começa o corpo do cliente hospitalizado uma vez que ele está num ambiente repleto de máquinas e acessórios necessários ao cuidado? Até que ponto os profissionais de saúde tem refletido sobre o quanto os fatores ambientais, no âmbito do cuidar efetivo da clientela idosa, influenciam no resultado do cuidado prestado? Como utilizar o meio ambiente sem negligenciar as atribuições profissionais, os valores humanísticos e os recursos comunicacionais de forma a favorecer o cuidado?

A referida pesquisa baseou-se no referencial de estudos sobre a codificação não verbal da comunicação humana ${ }^{(6)}$, tendo os fatores ambientais como uma das dimensões que permeiam e transmitem informações sobre as pessoas (objetos de decoração, escolha das cores, disposição da mobília e uso do espaço). Nesta perspectiva, refletir constantemente sobre como que as implicações do ambiente interferem no desenvolvimento do cuidado de enfermagem em gerontologia efetivo é um caminho adequado na busca da comunicação humana de qualidade na saúde.

\section{OBJETIVO}

Verificar os fatores ambientais, identificados por graduandos e graduados da área de saúde, que interferem na comunicação com o idoso.

\section{MATERIAL E MÉTODO}

Estudo exploratório com abordagem qualitativa, desenvolvido no interior paulista após aprovação do Comitê de Ética em Pesquisa com Seres Humanos (Processo CEP/HRA n ${ }^{\circ}$ 167/2008) com 117 graduandos e profissionais da saúde (medicina, enfermagem, fisioterapia, psicologia, educador físico, 
serviço social) que participaram da capacitação em comunicação não verbal em gerontologia( ${ }^{(8)}$.

O programa de capacitação respeitou uma matriz pedagógica que continha as bases teóricas, os recursos e procedimentos pedagógicos que incluíram leitura de poemas, exibição de imagens do idoso com texto reflexivo, discussão em arena das vivências e aula dialogada. A matriz foi elaborada de forma que, ao final de cada encontro, o participante pudesse revelar seu grau de assimilação.

Dentre os objetivos dessa capacitação estavam a identificação dos aspectos/fatores ambientais capazes de auxiliar na comunicação não verbal com a pessoa idosa. Para obtenção dos dados apresentados neste estudo utilizou-se a questão: "Identifique fatores ambientais que podem interferir na comunicação com idoso". A questão foi aplicada pela primeira autora deste estudo, que desenvolveu o programa, imediatamente após o segundo encontro, que teve a duração de 4 horas e foi realizado em janeiro/2009 (dentre um total de três encontros realizados na capacitação), quando essa temática foi discutida ${ }^{(8)}$.

Após assinatura do Termo de Consentimento Livre e Esclarecido, com todos os itens da Resolução 196/96, para garantir o anonimato dos participantes, foram recolhidas as folhas de resposta, sem fazer anotações que pudessem identificá-los, somente com a letra $\mathrm{P}$ de participante seguida do número arábico sequencial. As respostas foram lidas e corrigidas frente ao gabarito teórico utilizado na capacitação ${ }^{(6,7)}$. O tratamento dos dados foi realizado por meio da leitura e classificação das respostas de cada pergunta existente na avaliação, quando a pesquisadora destacou a essência do pensamento escrito. Diante disso, foi possível agrupar as respostas e definir os títulos dos agrupamentos. Ressalta-se que uma resposta pode pertencer a mais de um tipo de agrupamento, pois mais de um fator ambiental pode ter sido citado em cada resposta.

\section{RESULTADOS}

Foram submetidos à capacitação em comunicação não verbal em gerontologia 117 pessoas sendo: 71,8\% (84) de profissionais de saúde e 28,2\% (33) de graduandos na área da saúde. Em relação ao gênero e idade 80,3\% (94) eram muIheres com idade média de 35,7 anos e 19,7\% (23) homens com 29,6 anos em média, de idade. A média geral de idade dos participantes, independentemente do gênero, foi de 34,5 anos, tendo o mais novo 20 anos e o mais velho 59 anos.

As respostas dos participantes da capacitação, no que tange aos fatores ambientais que poderiam auxiliar na comunicação, puderam ser ordenadas e analisadas em sete agrupamentos distintos, a saber: sonoros e vibratórios; decorativos e espaciais; luminosos; cores e texturas; térmicos e ventilatórios; higiênicos e de segurança profissionais e sinalizadores visuais.

O primeiro agrupamento, sonoros e vibratórios (97 $82,9 \%$ ), agregou respostas que citaram os ruídos e barulhos desencadeados pelo uso de carrinhos de banho, carrinhos de limpeza, carrinhos de distribuição de refeições, carrinhos de recolhimento e entrega de roupas, equipamentos de uma maneira geral, uso de celulares com toques fortes e até inadequados, uso de sapato barulhento pela equipe de profissionais; música alta e inadequada para o ambiente hospitalar, televisores e rádios ligados até tarde da noite. Exemplos de respostas:

Tudo bem que precisamos de celular, mas será que não dá para escolher toque mais adequado e menos alto, uns até assustam o coitado do idoso; o barulho da caldeira vem direto para algumas enfermarias e esses carrinhos da nutrição são um escândalo (P23)

Várias pessoas no mesmo lugar, falando ao mesmo tempo, barulho produzido pelo carrinho de banho e de alimentação. (P108)

Decorativos e espaciais $(67-57,3 \%)$ foi o agrupamento que englobou respostas que mencionaram a ocupação dos espaços pela distribuição dos mobiliários; presença de obstáculos nos corredores; espaçamento entre os leitos, não garantindo conforto e privacidade ao idoso; tipo, qualidade e disposição dos objetos; qualidade e adequação (tamanho e altura) dos mobiliários. Exemplos:

... mesa do profissional no momento da entrevista e o que tem em cima dela pode ser uma barreira, pois se é muito sofisticada e bacana, o idoso fica com vergonha e não conta o que precisa contar. (P69)

A maioria dos idosos usa cadeira de rodas ou andador e tanto os corredores como os espaços entre os leitos são estreitos, um invade o espaço do outro. (P112)

O grupo intitulado de luminosos (51 - 43,6\%) reuniu as respostas que referenciaram o tipo, qualidade e intensidade da luz do quarto, da cabeceira e do próprio equipamento médico hospitalar. Eis dois exemplos:

Confesso que descobri que eu já fiz coisa errada, principalmente para quem está usando monitor cardíaco. Vou lá e vejo o traçado e, muitas vezes, esqueço de olhar o paciente...luminosidade demais na UTI irrita, pois impede de dormir.(P05)

Parece simples, porém a luz na cabeceira ajuda o idoso a levantar de noite da cama, mas ela acesa na cara dele, impede até dele dormir e enxergar a gente.

O agrupamento cores e texturas (38 - 32,5\%) foi composto pelas respostas que recordaram a influência na comunicação das cores usadas em paredes e portas, nos consultórios, corredores, e até nas roupas de cama.

... tudo que está no ambiente pode ajudar ou atrapalhar na conversa com o idoso, desde a estrutura arquitetônica até os aspectos ligados às cores usadas; não é à toa que centro cirúrgico não é vermelho. (P 15) 
Corredor com cor forte pesa no ambiente e pode até deprimir. Então ele já chega aqui triste, porque está percebendo que o lugar não é aconchegante e dependendo da cor atrapalha para saber se está ou não ictérico (P91)

Já o agrupamento denominado térmicos e ventilatórios (29-24,8\%) reuniu as respostas que mencionaram a temperatura alta ou baixa do ambiente, o uso indiscriminado de ar condicionado nas unidades de Centro Cirúrgico e de Terapia Intensiva, aeração e ventilação dos quartos e banheiros, além da abertura das janelas como fatores que interferem na comunicação. Eis exemplos:

Não podemos esquecer que o ar condicionado deixa o ambiente bom, mas na verdade fica bom para o pessoal. No fundo, não lembramos que os pacientes precisam de cobertor, não percebemos que ele está com frio e, assim, ele não se sente confortável, consequentemente, não interage. (P34)

Não só o visual pode ser observado pela janela, mas o frescor que vem dela traz ao idoso recordação que pode auxiliar na comunicação dele com os demais pacientes do quarto e com os demais (P75)

Higiênicos e de segurança profissional (14 - 11,9\%) foi o agrupamento que englobou as respostas que valorizaram a limpeza e organização do quarto e banheiro, retirada de lixo por conta da liberação de odores, e pisos escorregadios como pontos que influenciam a comunicação e a segurança. Exemplos:

... limpeza do quarto, cheiro do quarto e do banheiro. (P49)

O cheiro bom aproxima as pessoas, mas o cheiro do papagaio, lixo aberto e ares do banheiro acabam afastando o profissional de ficar perto do paciente; encurtamos a conversa com ele. Além de ainda oferecer risco para doenças e infecções. (P102)

Finalmente, o sétimo agrupamento denominado sinalizadores visuais $(2-1,8 \%)$ foram as respostas que expressaram o quanto a comunicação visual com o uso de placas expõe ou confunde o cliente; o uso de faixas no chão, nem sempre privilegia o entendimento ou garante a informação atualizada.

Excesso de informação visual, monte de faixas coloridas no chão, até que ponto isso é informação?. (P10)

A maioria dos idosos que tem problemas de visão fica perdida dentro do serviço. Muitos tem letra pequena que não localiza ele, ao contrário, atrapalha. ( $P$ 93)

\section{DISCUSSÃO}

Os aspectos sonoros e vibratórios foram os fatores ambientais mais citados $(82,9 \%)$, sendo que as respostas mais frequentes referiam-se aos ruídos e barulhos desencadeados pelo uso de carrinhos e bater das portas, ao uso de celulares com sinais inadequados, à utilização de rádios e televisores ligados até o avançar da noite, dentre outros.

Durante os últimos anos o desenvolvimento e o acesso às técnicas e dispositivos que facilitam e melhoram as condições de atendimento ao cliente tem trazido benefícios no sentido de diminuir o tempo de internação e aumentar a resposta terapêutica, entretanto, trouxe também um ambiente físico superestimulante ${ }^{(1)}$. Os resultados estão de acordo com autores ${ }^{(9)}$ que afirmam que o meio ambiente pode influenciar positiva ou negativamente a comunicação das pessoas idosas, dependendo da quantidade de estímulos a que estão expostas. Refletem o estudo desenvolvido em um hospital de São Paulo(10) onde se revelou que a queixa da maioria dos clientes em não conseguir dormir adequadamente estava associada às conversas em voz alta e ao barulho frequente e intenso, provocando ansiedade e apreensão e, ainda, o não desejo de interação com a equipe.

Parte da clientela idosa possui presbiacusia(11) e o barulho acaba por diminuir ainda mais sua habilidade auditiva. Além disso, interfere na fase do sono, causa irritabilidade e instabilidade das funções fisiológicas, como aumento da pressão arterial, alteração do ritmo cardíaco, vasoconstricção periférica e outros, o que atrapalha na sua recuperação(1).

Interessante citar pesquisa desenvolvida na Unidade de Terapia Intensiva ${ }^{(1)}$ que registrou no período da manhã níveis de ruídos sonoros mais altos, relacionado ao fluxo maior de pessoas, quantidade maior de atividades realizadas, como troca de equipamentos que facilitam o disparo de alarmes, coleta de exames e organização de leitos. Os autores ressaltam que os profissionais precisam se recordar dessa condição e atentar ao tom de voz tanto quando atendem aos telefones e conversam com as demais pessoas que lá trabalham.

Para 57,3\% dos participantes, os aspectos decorativos e espaciais como tipo e disposição dos objetos ornamentais, os obstáculos de corredores e espaçamento entre leitos foram os mais recordados como fatores de interferência na comunicação.

O ambiente físico e os objetos que o compõem são um constructo social, que revelam apropriação e demarcação da identidade do sujeito e do poder que ele exerce no meio. Quanto mais personalizado um espaço é, maior a margem de autonomia que se busca, pois de certa forma revela o grau de empoderamento e de influência que se tem ${ }^{(6,12)}$.

Os aspectos luminosos $(43,6 \%)$ englobaram as respostas que identificaram a presença da luz no ambiente como possibilidade de ajuda na interação com o cliente e o cuidado que o profissional deve tomar quando, sem perceber, cuida do equipamento existente, como um monitor cardíaco, e se esquece do cliente no ambiente. Esta situação nos leva a trazer a contribuição de autores ${ }^{(13)}$ que ressaltam que não é raro defrontar com excelentes técnicos, sumidades na habilidade de manipulação de equipamentos de ponta, mas que acabam comportando-se como calouros na arte de confortar o cliente, pois o identificam como um caso ou número e restringem sua atenção no que os aparelhos revelam. 
A luz, seja natural ou artificial, além de necessária para a realização de atividades, contribui para a composição de uma ambiência aconchegante; entretanto, cabe ao profissional ater-se no sentido de respeitar a privacidade e o descanso do cliente. Não se pode esquecer também que a luz natural, quando presente no ambiente, ajuda o cliente a manter a noção de tempo (dia e noite, chuva ou sol) e isso influencia no seu estado de saúde ${ }^{(7)}$.

A Política Nacional do Idoso ${ }^{(14)}$ considera que adequadas instalações geriátricas, ou seja, uma planta física que favoreça não só a instalação de equipamentos para a segurança e locomoção do idoso hospitalizado, mas que facilite sua adaptação e convivência, sejam valorizadas e devam constituir uma realidade nos serviços de saúde que atendam as pessoas idosas.

Corrobora para este aspecto o documento sobre ambiência na saúde elaborado pelo Ministério da Saúde ${ }^{(7)}$, que trata dos fatores ambientais e cria três eixos, como busca contínua, que são: a confortabilidade focada na privacidade e individualidade das pessoas envolvidas, valorizando elementos do ambiente que interagem com as pessoas como: cheiro, cor, som, iluminação e morfologia; o espaço para reflexão, uma vez que constitui um lugar onde as pessoas se encontram, convivem e se relacionam; e o processo de trabalho, como uma ferramenta que possa favorecer e otimizar um atendimento acolhedor e resolutivo.

Como fator de influencia na comunicação com o idoso, as cores e texturas foram apontadas por 32,5\% dos participantes, principalmente as usadas nas paredes e na própria roupa de cama. Esse ponto é defendido por autora ${ }^{(15)}$, quando afirma que a cor do ambiente é um dos principais fatores determinantes da forma como as pessoas se relacionam com o ambiente e o que ele acaba transmitindo. Acrescenta que a cor interfere no estado emocional, na produtividade e na qualidade das atividades desenvolvidas, pois atrai a atenção de acordo com sua visibilidade, contraste e pureza.

Importante salientar que as cores neutras, suaves e foscas das paredes de áreas como centro cirúrgico, por exemplo, são para evitar a emissão de reflexos luminosos, a fadiga visual, o cansaço e os estímulos nervosos ${ }^{(16)}$.

Os aspectos ambientais ligados à temperatura e ventilação constituem uma realidade recordada por $24,8 \%$ dos participantes da pesquisa. Esse resultado remete ao estudo desenvolvido num hospital universitário carioca $^{(5)}$ que revelou o quanto o cliente é submetido às baixas temperaturas advindas da ventilação artificial necessária à manutenção do ambiente asséptico. Ressalta-se que apesar dos objetivos do uso do ar condicionado ser a remoção de gases anestésicos e partículas em suspensão, controle da temperatura e umidade, promoção da troca de ar adequada, bem como conforto ambiental, isto não justifica o esquecimento em manter o aquecimento corporal do cliente que lá se encontra e de repensar até que ponto o conforto está voltado para ambos (profissional e cliente).

Os fatores ambientais ligados ao odor e a segurança foram lembrados por $11,9 \%$ dos participantes. Vale ressaltar que as percepções olfativas são fundamentais no espaço do cuidar nos serviços de saúde, tendo em vista os inúmeros fatores existentes no seu cotidiano. Quando os odores se apresentam desagradáveis ao sentido, causam no indivíduo a sensação de desconforto geral, daí a importância que medidas sejam adotadas no sentido de contenção, dispersão ou eliminação dos mesmos. A literatura revela que as sensações olfativas interferem nas reações de caráter afetivo e terapêutico (humor, depressão, euforia, irritação, sedução), sendo a variação decorrente da percepção subjetiva e a interpretação da memória olfativa que todo indivíduo possui podendo ganhar representações distintas (positivas ou negativas) ${ }^{(17)}$.

Apesar de pouco citada, a comunicação visual feita por placas que expõem e confundem o idoso merece destaque $(1,8 \%)$, visto o grau de importância que esta pode assumir na comunicação. Estudiosos $^{(18)}$ na área ressaltam que a comunicação visual, desenvolvida por meio de sinalização, possui o intuito de informar, direcionar e orientar as pessoas para que consigam se locomover e encontrar o que procuram. Os autores destacam que em um ambiente hospitalar, a comunicação visual permite o poder de decisão e acesso à informação em um espaço onde a situação de desconforto emocional está quase sempre presente. Uma sinalização inadequada causa confusão, desorientação, irritação e perda de tempo, que no ambiente hospitalar é um item precioso. Contudo, para cada hospital é necessário um sistema de sinalização que se seja ajustado ao perfil que possui. Sendo assim, os profissionais de saúde precisam se ater a essa vertente que, muitas vezes, passa despercebida no cotidiano, como revela o relato de um dos participantes: "se nós ficamos confusos com tantas faixas coloridas nos corredores e com placas desatualizadas, imagina eles" (P 10).

No caso de idosos, além da visão geralmente acometida ${ }^{(11)}$, existem os aspectos ligados ao grau de instrução, uma vez que a maioria no País é analfabeta funcional, o que acaba por dificultar o acesso às informações ${ }^{(9)}$. Portanto, o uso adequado de tipografia e tamanho de letras, dimensão, posição, localização e altura das placas, até dos crachás dos profissionais, cores e figuras de fundo, em pontos estratégicos que facilite a compreensão, devem ser respeitados pela administração e pelos profissionais, pois precisam ser utilizados de maneira peculiar à clientela ${ }^{(19)}$.

Concordamos como o defendido por autores ${ }^{(20)}$ que afirmam que o que determina se o ambiente físico desumaniza ou despersonaliza não é a mobília traduzida pela presença dos equipamentos, organização dos espaços físicos ou a própria tecnologia existente nele, mas como as interações dos profissionais se dão com eles e por meio deles nos mais diferentes contextos do cliente, bem como os significados e intenções que são atribuídos à tecnologia em si. Se for a favor do humano terá resultado satisfatório, pois houve a inclusão do cliente nessa realidade, o que é efetivo e positivo.

\section{CONSIDERAÇÕES FINAIS}

De acordo com o objetivo proposto os fatores ambientais citados que interferem na comunicação com idoso foram àqueles ligados aos ruídos e barulhos, ocupação e organização do espaço, luminosidade, cores usadas, temperatura e ventilação e condições higiênicas que garantam a segurança do cliente. 
A realidade presente aos profissionais que estão inseridos nos serviços de saúde é do enfrentamento do ambiente de trabalho com inúmeras possibilidades de criar e recriar o cuidado tecnológico e humano com o idoso. Utilizar os fatores ambientais como uma possibilidade efetiva de assistência é importante e real, pois ela interfere no bem estar do idoso, na sua recuperação e no relacionamento entre o binômio profissional-idoso; o resultado positivo ou não dessa relação é dependente de como focamos e desejamos que a comunicação seja estabelecida e mantida.
Este estudo avança no conhecimento da área de enfermagem uma vez que expõe a percepção e a compreensão dos profissionais e graduandos de saúde do quanto os aspectos ambientais podem ser usados como coadjuvantes no tratamento holístico e integral do indivíduo. Aspecto esse defendido desde o primórdio da profissão por Florence Nightingale, quando afirma que as condições e influências externas, próprias do meio ambiente, afetam a vida e o desenvolvimento do organismo, sendo capazes de anteceder, eliminar ou contribuir para a saúde.

\section{REFERÊNCIAS}

1. Cardoso MVLML. Chaves EMC, Bezerra MGA. Ruídos e barulhos na unidade neonatal. Rev Bras Enferm 2010;63(4):561-6.

2. Marques IR, Souza AR de. Tecnologia e humanização em ambientes intensivos. Rev Bras Enferm 2010; 63(1):141-4.

3. Prochet T, Ruiz T, Correa I. A humanização do atendimento ao idoso: o que o idoso hospitalizado sente, percebe e deseja? Nurs 2006;94(9):713-18.

4. Nightingale F. Notas sobre enfermagem: o que é e o que não é. São Paulo: Cortez; 1989.

5. Silva DC, Alvim NAT. Ambiente do centro cirúrgico e os elementos que o integram: implicações para os cuidados de enfermagem. Rev Bras Enferm 2010;63(3):427-34.

6. Silva MJP. Comunicação tem remédio. São Paulo: Loyola; 2008.

7. Ministério da Saúde (Brasil), Secretaria de Atenção à Saúde. Núcleo Técnico de Política Nacional de Humanização. Ambiência. 2. ed. Brasília; 2007.

8. Prochet TC. Capacitação em comunicação não verbal: um caminho para ações de cuidado efetivo/afetivo ao idoso. São Paulo. Tese [Doutorado em Enfermagem]- Universidade de São Paulo; 2010.

9. Pires ZRS, Silva MJ. Autonomia e capacidade decisória dos idosos de baixa renda: uma problemática a ser considerada na saúde do idoso. Rev Eletrônica Enferm [periódico na internet]. 2001 [acesso 12 jan 2011 ];3(2) Disponível em: <http://www.fen.ufg.br/revista/revista3_2/ autonomia.html $>$.

10. Salomé GM, Guerra CA. Sentimentos dos pacientes infartados durante o período de internação em uma UTI. Enferm Brasil 2003;2(3):171-6.

11. Tannure MC, Alves M, Sena RR de, Chianca TCM. Perfil epidemiológico da população idosa de Belo Horizonte, MG, Brasil. Rev Bras Enferm 2010;63(5):817-22.
12. Fischer G. Espaço, identidade e organização. In: Chanlat J. O indivíduo na organização: dimensões esquecidas. São Paulo: Atlas; 1996. p.82-102.

13. Hayashi AAM, Gisi ML. O cuidado humanístico num contexto hospitalar. Rev Texto \& Contexto 2000; 9(2):800-11.

14. Ministério da Saúde (Brasil). Portaria $n^{\circ}$. 2.528, de 19 de outubro de 2006. Aprova a Política Nacional de Saúde da Pessoa Idosa. Diário Oficial da União 20 out 2006

15. Farina $M$, Perz $C$, Bastos D. Psicodinâmica das cores em comunicação. 5. ed. São Paulo: Edgard Blücher; 2006.

16. Ministério da Saúde (Brasil), Agência Nacional de Vigilância Sanitária. Resolução RDC no.50/2002, 21 fevereiro de 2002. Dispõe sobre normas destinadas ao exame e aprovação dos projetos físicos de estabelecimentos de serviços de saúde. [resolução na internet]. Diário Oficial da União 21 fev 2002. Disponível em: < http://anvisa. gov.br/legis/resol/2002/50_02rdc.pdf>.

17. Wosny A de M, Erdmann AL, Filho PB, Leite JL. Estética dos odores: o sentido do olfato e a enfermagem. Rev Latino-am. Enferm 2008;16(2):320-3.

18. Guimarães $\mathrm{CP}$, Vendramini C. Comunicação visual: orientação de fluxos e identificação de ambiente em um hospital. Rev Ambiente Hospitalar [periódico na Internet]. 2007 [acesso em 7 nov 2009];1(2) Disponível em: <http://www.flexeventos.com.br/portal/secoes/ artigos/365,comunicacao-visual.aspx $>$.

19. Ferreira AMTGB. Ouvindo o idoso hospitalizado: direitos envolvidos na assistência cotidiana de Enfermagem. São Paulo. Tese [Mestrado em Enfermagem]- Universidade de São Paulo; 2005.

20. Barra DCC, Nascimento ERP, Martins JJ, Albuquerque GL, Erdman AL. Evolução histórica e impacto da tecnologia na área da saúde e de enfermagem. Rev Eletrônica Enferm 2006;8(3):422-30. 